\title{
VIRAL HEPATITIS, HIV, HUMAN HERPES VIRUS AND TREPONEMA PALLIDUM INFECTION IN HAEMODIALYSIS PATIENTS FROM KOSOVO, 2005
}

\author{
G L Quaglio (gianluca.quaglio@azosp.vr.it) ${ }^{1}$, C Pattaro², N Ramadani ${ }^{3}$, L Bertinato ${ }^{1}$, Y Elezi ${ }^{4}$, P Dentico 5 , A Volpe ${ }^{5}$, M Ciotti ${ }^{6}$, G \\ Rezza ${ }^{7}$, G Putoto ${ }^{1}$ \\ 1. Veneto Region, Italian Co-operation, Peja Training Project Team, Venice, Italy \\ 2. European Academy (EURAC), Bozen/Bolzano, Italy - Affiliated Institute of the University Lübeck, Germany \\ 3. National Institute of Public Health, Pristhine, Kosovo \\ 4. Nephrology Unit, Department of Internal Medicine, University of Prishtine, Kosovo \\ 5. Institute of Internal Medicine, University of Bari, Italy \\ 6. European Centre for Disease Prevention and Control, Stockholm, Sweden \\ 7. Department of Infectious Diseases, Istituto Superiore di Sanità, Rome, Italy
}

This article was published on 10 December 2009.

Citation style for this article: Quaglio GL, Pattaro C, Ramadani N, Bertinato L, Elezi Y, Dentico P, Volpe A, Ciotti M, Rezza G, Putoto G. Viral hepatitis, HIV, human herpes virus and Treponema pallidum infection in haemodialysis patients from Kosovo, 2005. Euro Surveill. 2009;14(49):pii=19439. Available online: http://www.eurosurveillance.org/ ViewArticle.aspx?ArticleId $=19439$

\begin{abstract}
The serological status of hepatitis viruses and other infectious diseases in the 66 dialysed patients of one haemodialysis unit in Kosovo were studied, comparing the data with a large group of blood donors and out-patients. All dialysed patients were hepatitis $A$ virus (HAV) positive. Prevalence of hepatitis B surface antigen (HBsAg), hepatitis B surface antibodies (anti-HBs), and hepatitis B core antibodies (anti-HBc) was 14 of $66,21 \%$ (95\% confidence interval (Cl): $12-33 \%), 5$ of $66,8 \%(95 \% \mathrm{Cl}: 5-22 \%)$, and 50 of $66,76 \%(95 \% \mathrm{Cl}: 64-85 \%)$, respectively. Antibodies to hepatitis C virus (anti-HCV) prevalence was 57 of $66,86 \%$ (95\% Cl: $76-94 \%$ ). No human immunodeficiency virus (HIV) positive case was found. Prevalence of past herpes simplex virus type 2 (HSV-2) infection was $29 \%$ (95\% $\mathrm{Cl}$ : $18-41 \%)$. Two patients (3\%, 95\% Cl: $0-10 \%)$ were positive for Treponema pallidum and 18\% (95\% Cl: $10-30 \%)$ were human herpesvirus $8(\mathrm{HHV}-8)$ antibody positive. Four hundred and fifty-two subjects were recruited for comparison. Markers of past HAV infection was associated with haemodialysis (Fisher's exact test $p$-value $=0.037$ ). Dialysed patients were at a higher risk of being HBsAg positive than others: the sex- and age-adjusted odds ratio (OR) was $5.18(95 \% \mathrm{Cl}$ : 1.87-14.32). Anti-HBc positivity was strongly associated with haemodialysis: the sex- and age-adjusted OR was 6.43 (95\%Cl: 3.22-12-85). Anti-HCV positivity was $86 \%$ and $1 \%$ in presence and absence of haemodialysis, respectively. The Fisher's exact test for association proved a strong association between haemodialysis and HCV ( $p$-value $<0.0001)$. The OR for association between haemodialysis and HSV-2 positivity was 3.20 (95\% Cl: 1.46-7.00). Significant associations were also observed between haemodialysis status and antibodies to Treponema pallidum (Fisher's exact test $\mathrm{p}$-value $=0.044$ ). In Kosovo, the prevalence of viral hepatitis infection and other viral infections and Treponema pallidum among dialysed patients is high, indicating major ongoing nosocomial transmission.
\end{abstract}

\section{Introduction}

The population of Kosovo has suffered substantially after the break-up of the former Yugoslavia in the early 1990ies and the consequent armed conflict in 1999. Recently, the region has acquired a national autonomy, with some limitations of sovereignty and with the support of the European Union [1]. In 2006, the population was estimated at 1.9 million and was one of the youngest in Europe. About $37 \%$ lived in poverty; unemployment was estimated at around $40 \%$, with a gross domestic product per capita of 834 EUR in 2006 (468 EUR in 2000) [2]. Health indicators remained among the most unfavourable in the Balkan region. The annual per capita government expenditure on health care was 35 EUR, the lowest in Europe. Kosovo had one of the highest perinatal mortality rates (23 per 1,000 live births) in Europe and the number of physicians per 1,000 inhabitants was 0.94 [3]. The transition to more modern concepts of health care management presented a challenge to health personnel and the population after the war. Currently, the healthcare system consists of primary centers located in each municipality, secondary health care facilities at the regional level (five hospitals), and tertiary health care centers (University of Pristine and a few other specialised institutions).

After the conflict, the number of end-stage renal disease (ESRD) patients progressively increased in Kosovo: from 190 in 1999 to approximately 600 in 2007 . The rate of patients in DC treatment in Kosovo is 286 per million, lower than in other Central and Eastern European countries [4]. At the time of our study, patients were treated in six different dialysis centres (DC), with standard twice or three times a week five hour dialysis sessions (10\% and $90 \%$, respectively). We examined patients at the DC in Peja hospital which had no special areas dedicated to patients with positive history of hepatitis.

A number of reports have shown that viral hepatitis $B$ (HBV) and viral hepatitis C (HCV) are common among ESRD patients [5-7]. In the dialysis centres of Kosovo and of other Eastern European countries, the prevalence of such infections has been poorly investigated. The few existing studies suggest that the prevalences are higher in patients dialysed in this part of Europe compared with other European countries [8-11]. The aim of this study was to 
analyse the prevalence of viral hepatitis and other infections such as HIV, HVS-2, HHV-8 and syphilis in the ESRD patients of the hospital in the Peja region. Furthermore, we wanted to investigate whether the haemodialysis was associated with an elevated risk of infections. Our study was part of a survey carried out in the period 2004-2007 during a training project for healthcare workers at the hospital in the Peja region, supported by the Veneto Regional Health Authority and the Italian Co-operation Agency [12].

TA B L E 1

General characteristics of the 66 haemodialysis patients, compared to 452 non-haemodialysed patients $(n=518)$

\begin{tabular}{|c|c|c|c|c|c|c|}
\hline \multirow[t]{3}{*}{ Characteristics of patients } & \multicolumn{5}{|c|}{ Haemodialysis } & \multirow{3}{*}{$\begin{array}{c}\text { Chi-square homogeneity test } \\
\text { p-value }\end{array}$} \\
\hline & \multicolumn{2}{|c|}{ Yes } & \multicolumn{2}{|c|}{ No } & \multirow[b]{2}{*}{$\%$} & \\
\hline & & $\mathrm{N}$ & $\%$ & $\mathrm{~N}$ & & \\
\hline \multirow[t]{2}{*}{ Sex } & Females & 27 & 41 & 296 & 65 & $<0.01$ \\
\hline & Males & 39 & 59 & 156 & 35 & \\
\hline \multirow[t]{3}{*}{ Age } & $18-30$ & 3 & 4 & 185 & 41 & $<0.01$ \\
\hline & $30-50$ & 21 & 32 & 220 & 49 & \\
\hline & $50+$ & 42 & 64 & 47 & 10 & \\
\hline \multirow[t]{2}{*}{ Domicile } & Urban & 21 & 32 & 173 & 38 & 0.31 \\
\hline & Rural & 45 & 68 & 279 & 62 & \\
\hline \multirow[t]{2}{*}{ Education } & $\leq 8$ & 52 & 79 & 105 & 23 & $<0.01$ \\
\hline & $>8$ & 14 & 21 & 347 & 77 & \\
\hline \multirow[t]{2}{*}{ Married } & No & 8 & 12 & 165 & 63 & $<0.01$ \\
\hline & Yes & 58 & 88 & 287 & 37 & \\
\hline \multirow[t]{2}{*}{ Employed } & No & 42 & 64 & 109 & 24 & $<0.01$ \\
\hline & Yes & 24 & 36 & 343 & 76 & \\
\hline \multirow[t]{2}{*}{ Blood transfusion } & No & 2 & 3 & 442 & 98 & $<0.01$ \\
\hline & Yes & 64 & 97 & 10 & 2 & . \\
\hline \multirow[t]{3}{*}{ Dialysis (months) } & $0-24$ & 28 & 42 & - & - & - \\
\hline & $24-48$ & 13 & 20 & - & - & - \\
\hline & $48+$ & 25 & 38 & - & - & - \\
\hline \multirow[t]{2}{*}{ Pts. always in the same unit } & No & 5 & 7 & - & - & - \\
\hline & Yes & 61 & 93 & - & - & - \\
\hline Total & & 66 & 100 & 452 & 100 & \\
\hline
\end{tabular}

TA B L E 2

Seroprevalence of viral hepatitis, HIV, HSV-2, Treponema pallidum and HHV-8 of patients in haemodialysis, compared to non-haemodialysed patients

\begin{tabular}{|c|c|c|c|c|c|c|c|}
\hline \multirow{3}{*}{ Serology } & \multicolumn{4}{|c|}{ Haemodialysis } & \multirow{3}{*}{ Fisher's exact test p-value } & \multirow{3}{*}{ Crude OR (95\%CI) } & \multirow{3}{*}{ Sex- and age-adjusted OR (95\%CI) } \\
\hline & \multicolumn{2}{|c|}{ yes } & \multicolumn{2}{|c|}{ no } & & & \\
\hline & $\mathrm{N}$ & $\%$ & $\mathrm{~N}$ & $\%$ & & & \\
\hline $\operatorname{HAV}^{1}$ & 66 & 100 & 424 & 94 & 0.037 & $\mathrm{NE}$ & $\mathrm{NE}$ \\
\hline $\mathrm{HBSAg}^{2}$ & 14 & 21 & 16 & 3 & $<0.0001$ & $7.34(3.39,15.89)$ & $5.18(1.87,14.32)$ \\
\hline $\mathrm{HBsAb}^{3}$ & 5 & 8 & 69 & 15 & 0.13 & $0.45(0.18,1.17)$ & $0.27(0.09,0.79)$ \\
\hline $\mathrm{HBCAb^{4 }}$ & 50 & 76 & 107 & 24 & $<0.0001$ & $10.08(5.51,18.42)$ & $6.43(3.22,12.85)$ \\
\hline HBV $\operatorname{vax}^{5}$ & 2 & 3 & 0 & 0 & 0.016 & $\mathrm{NE}$ & $\mathrm{NE}$ \\
\hline $\mathrm{HDV}^{6}$ & 1 & 1 & 0 & 0 & 0.127 & NE & $\mathrm{NE}$ \\
\hline $\mathrm{HCV}^{7}$ & 57 & 86 & 3 & 1 & $<0.0001$ & $947.89(249.39,3602.83)$ & $\mathrm{NE}$ \\
\hline HIV $^{8}$ & 0 & 0 & 0 & 0 & 1 & $\mathrm{NE}$ & $\mathrm{NE}$ \\
\hline HSV- $2^{9}$ & 19 & 29 & 45 & 10 & $<0.0001$ & $3.66(1.98,6.77)$ & $3.2(1.46,7)$ \\
\hline T. pallidum ${ }^{10}$ & 2 & 3 & 1 & 0.2 & 0.044 & $14.09(1.26,157.66)$ & NE \\
\hline HHV- $8^{11}$ & 12 & 18 & - & - & - & - & - \\
\hline
\end{tabular}

In bold: results significant at an alpha $\leq 0.05$. Abbreviations used: OR: odds ratio; NE: not estimable; 1 : hepatitis A virus; 2 : hepatitis B surface antigen; 3: hepatitis B surface antibody; 4: hepatitis B core antigen: 5: HBV vaccinated subjects; 6: hepatitis delta virus; 7: hepatitis C virus; 8: human immunodeficiency virus: 9: human herpes virus 2; 10: Treponema pallidum; 11: human herpes virus 8 


\section{Methods}

Field work for this cross-sectional study was conducted from 1 January 2005 to 30 March 2005. The association between the prevalence of viral hepatitis and other infections and the haemodialysis status was assessed by comparing the ESRD patients with a group of blood donors and subjects who had been examined for routine laboratory testing. In addition, the scientific literature was reviewed to compare the HBV and HCV prevalence of patients in DC of different Eastern and Western European countries.

\section{Study population}

All 66 ESRD patients treated at the DC of Peja regional hospital were enrolled in the study. Candidate blood donors being screened for donation suitability and individuals ( 18 years of age and older) who had undergone routine check-ups in two clinics in Peja and whose serum was sent for routine testing, were included in the study as a comparison group. In order to approximately randomise the group, patients screened on Monday, Wednesday and Friday were selected. In the three months of the study period, 285 blood donors and 187 subjects examined in clinics were potentially eligible for comparison. Out of the total number of 472 subjects, 20 refused to be tested or to respond to the questionnaire. The final number of 452 subjects was recruited. Approval from the Kosovo Institute of Public Health, the Regional Health Authorities and the Ethical Committee of the Peja region was obtained and a signed informed consent form from each participant was requested before entering the study.

TA B L E 3

HBsAg prevalence in haemodialysis centres in Western and Eastern European countries. Data on the general population is reported for comparison

\begin{tabular}{|c|c|c|c|c|c|c|}
\hline \multirow{2}{*}{ Country } & General & \multirow{2}{*}{ Year } & \multirow{2}{*}{ Reference } & \multirow{2}{*}{ Haemodialysis Centres } & \multirow{2}{*}{ Year } & \multirow{2}{*}{ Reference } \\
\hline & population & & & & & \\
\hline \multicolumn{7}{|c|}{ North European countries } \\
\hline Germany & $0.60 \%$ & 1998 & Thierfelder & $4.60 \%$ & 2001 & Burdick \\
\hline UK & $<0.5 \%$ & 2001 & Eurohep & $<0.5 \%$ & 2001 & Burdick \\
\hline \multicolumn{7}{|c|}{ South European countries } \\
\hline Italy & $1 \%$ & 2001 & Eurohep & $4.30 \%$ & 2001 & Burdick \\
\hline Spain & $1.70 \%$ & 2001 & Solà & $3.10 \%$ & 2001 & Burdick \\
\hline \multicolumn{7}{|c|}{ Eastern European countries } \\
\hline Moldovia & $9 \%$ & 2004 & Emiroglu & $17 \%$ & 1999 & Covic \\
\hline Romania & $6 \%$ & 2001 & Eurohep & $22 \%$ & 1998 & Vladutiu \\
\hline Bulgaria & $5 \%$ & 2001 & Eurohep & - & - & - \\
\hline Serbia & - & - & - & $15 \%$ & 1999 & Djukanovic \\
\hline
\end{tabular}

TA B L E 4

HCV prevalence in haemodialysis centres in Western and Eastern European countries 1997-2001. Data on the general population is reported for comparison

\begin{tabular}{|c|c|c|c|c|c|c|}
\hline Country & $\begin{array}{c}\text { General } \\
\text { population }\end{array}$ & Year & Reference & Haemodialysis centres & Year & Reference \\
\hline \multicolumn{7}{|c|}{ North European countries } \\
\hline Germany & $0.60 \%$ & 1999 & Esteban & $3.80 \%$ & 2003 & Fissell \\
\hline UK & $1 \%$ & 2001 & Bird & $2.60 \%$ & 2003 & Fissell \\
\hline \multicolumn{7}{|c|}{ South European countries } \\
\hline Italy & $3.50 \%$ & 1997 & Esteban & $20.50 \%$ & 2003 & Fissell \\
\hline Spain & $2.50 \%$ & 2001 & Dominguez & $22.90 \%$ & 2003 & Fissell \\
\hline \multicolumn{7}{|c|}{ Eastern European countries } \\
\hline Moldavia & $5 \%$ & 1997 & Covic & $75 \%$ & 1999 & Covic \\
\hline Romania & $6 \%$ & 2001 & Esteban & $73 \%$ & 1998 & Vladutiu \\
\hline Bulgaria & $3 \%$ & 2001 & Esteban & $48 \%$ & 2008 & Atanasova \\
\hline Poland & $2 \%$ & 2001 & Esteban & $44 \%$ & 1999 & Jadoul \\
\hline Hungary & $0.50 \%$ & 2001 & Müller & $15 \%$ & 1999 & Jadoul \\
\hline Serbia & - & - & - & $23 \%$ & 1999 & Djukanovic \\
\hline
\end{tabular}




\section{Questionnaire}

For all study participants information on socio-demographic characteristics and information related to haemodialysis treatment were collected by local physicians and nurses, interviewing patients using a structured questionnaire. The questionnaire included queries on age, sex, occupation, education, area of residence, partner status, length of dialysis treatment, number of transfusion received and if the patient remained always in the same unit of treatment. The serum was collected for laboratory investigations.

\section{Laboratory investigations}

The collected serum was tested for the following hepatitis markers: total anti-HAV (IgG and IgM), HBsAg, anti-HBs, total anti-HBc (IgG and IgM), and anti-HCV using AxSYM microparticle enzyme immunoassay (MEIA) (Abbott Diagnostics, North Chicago IL). HBsAg-positive subjects were tested for antibodies to hepatitis delta virus (anti-HDV IgG) using a commercial enzyme-linked immunosorbent assay test (ELISA) (DiaSorin, Saluggia, Italy). A line immunoassay (LIA) (INNO-LIA HIV I/II Score, Innogenetics N.V., Gent, Belgium) was used for detecting antibodies to HIV type 1 and 2, and samples that were reactive were confirmed with Western blot. To detect anti-HSV-2 antibodies, a commercial HSV-2 specific IgG enzyme immunoassay (EIA) (HSV 2 IgG EIA WELL, Radim, Pomezia, Italy) was used. IgG and IgM antibodies to Treponema pallidum were detected by a Treponema pallidum recombinant EIA (Syphilis Screening Recombinant EIA WELL, Radim, Pomezia, Italy). HHV-8 serum antibodies were detected by a commercially available ELISA assay (HHV-8 IgG Elisa, Advanced Biotechnologies Incorporated, Columbia, MD, Unites States). All tests were performed according to the manufacturer's instructions at the Istituto Superiore di Sanità Laboratory, Rome, Italy, and partner institutions.

\section{Statistical analysis}

Prevalence of viral hepatitis and other infectious diseases in haemodialysis patients was estimated and 95\% confidence intervals $(\mathrm{Cl})$ calculated. We tested whether viral hepatitis and other infectious diseases were associated with haemodialysis by comparing seroprevalence in dialysis patients to seroprevalence in two comparison groups: blood donors and subjects who had been examined in clinics. At a first stage, association was tested separately in dialysis patients vs. blood donors, and in dialysis patients vs. patients who had been examined in clinics. Provided that the estimates were homogeneous in the two analyses, the two groups were pooled together to form a unique comparison group. To account for data sparseness, association was tested by means of Fisher's exact test. Odds ratios (OR) and 95\% $\mathrm{Cl}$ were calculated using logistic regression models. All statistical analyses were performed using R 2.8.0 [13].

\section{Results}

Sixty-six haemodialysis patients were recruited (males: 59\%, mean age: $55 \pm 14$ years). The patient characteristics are reported in Table 1 . The duration of haemodialysis treatment ranged from 12 to 264 months (median time 48 months). Concerning the aetiology of ESRD, glomerulonephritis was the first cause (20 cases, $30 \%$ ), followed by diabetes mellitus (12 cases, 18\%), pyelonephritis (9 cases, 14\%), hypertension (7 cases, 10\%), polycystic kidney diseases ( 4 cases, $6 \%$ ), and systemic diseases (2 case, $3 \%$ ). Aetiology was unknown for 12 cases (19\%) of haemodialysis patients.
When comparing the distribution of hepatitis status in ESRD patients with subjects not undergoing haemodialysis, we found consistent results. Here we present results to the comparison between haemodialysis patients and the pooled group of comparison subjects. In total, 452 individuals (males: 35\%, mean age: $34 \pm 11$ years) were recruited for comparison. Participants' characteristics were all heterogeneous between haemodialysis and non-haemodialysis patients, except for the domicile ( $p$-value=0.31) (Table 1).

\section{Serological status of dialysed patients}

All ESRD patients were HAV positive indicating previous infection (Table 2). Prevalence of $\mathrm{HBsAg}, \mathrm{HBsAb}$, and $\mathrm{HBcAb}$ was 14 of $66,21 \%(95 \% \mathrm{Cl}: 12-33 \%), 5$ of $66,8 \%(95 \% \mathrm{Cl}: 5-22 \%)$, and 50 of $66,76 \%(95 \% \mathrm{Cl}: 64-85 \%)$, respectively. Two patients had been vaccinated for HBV. One male patient in his late forties was the only patient positive for HDV: he was also positive for HAV, $\mathrm{HBV}(\mathrm{HBcAb})$ and anti-HCV. HCV prevalence was 57 of $66,86 \%$ (95\% $\mathrm{Cl}: 76-94 \%)$. Concerning the co-occurrence of HBV and HCV in haemodialysis patients, we observed that $45(70 \%, 95 \% \mathrm{Cl}: 58-$ $81 \%)$ were both HBV (HBcAb) and HCV, 10 (16\%, 95\%Cl: 8-27\%) had $\mathrm{HCV}$ but no $\mathrm{HBV}$, five $(8 \%, 95 \% \mathrm{Cl}: 3-17 \%)$ had $\mathrm{HBV}$ but no $\mathrm{HCV}$, and four $(6 \%, 95 \% \mathrm{Cl}: 2-15 \%)$ had none (Fisher's exact test p-value $=0.096$ ).

No HIV positive case was found. Prevalence of HSV-2 was 19 of $66,29 \%(95 \% \mathrm{Cl}$ : $18-41 \%)$. Two patients (3\%, 95\% Cl: $0-10 \%)$ were positive for Treponema pallidum and 12, 18\% (95\% Cl: $10-$ $30 \%$ ) were HHV-8 positive.

HAV was associated with the haemodialysis status (Fisher's exact test $p$-value $=0.037$ ). Given that all dialysed patients were HAV positive, the estimation of OR was not possible. ESRD patients were at a higher risk of being HBsAg positive than others: sex- and ageadjusted OR was 5.18 (95\% Cl: 1.87-14.32). When additionally adjusting for the level of education, employment, marital status, and domicile, the OR increased up to $7.92(95 \% \mathrm{Cl}: 2.31-27-$ 12). HBcAb positivity was strongly associated with haemodialysis: the sex- and age-adjusted OR was 6.43 (95\% $\mathrm{Cl}$ : 3.22-12-85); it increased slightly when further adjusting for education, employment, marital status, and domicile as well to OR $6.9(95 \% \mathrm{Cl}$ : 3.17 15.03). HCV prevalence was $86 \%$ and $1 \%$ in presence and absence of haemodialysis treatment, respectively. For ESRD patients and the comparison group an OR could not be calculated. However, the Fisher's exact test for association proved a strong association between haemodialysis and HCV (p-value $<0.0001)$. The OR for association between haemodialysis and HSV-2 positivity was 3.20 (95\% $\mathrm{Cl}: 1.46-7.00)$ when adjusting for sex and age, and rising up to $6.44(95 \% \mathrm{Cl}: 2.40-17.27)$ when further adjusting for education, employment, marital status, and domicile. Significant associations were also observed between haemodialysis status and Treponema pallidum status (Fisher's exact test $p$-value $=0.044$ ). Results of the association study are reported in Table 2.

\section{Prevalence of HBV and HCV in DC of Eastern and Western European countries}

Table 3 shows the prevalence of serological markers for HBV in DC of Northwestern European countries, Southwestern European countries and Eastern European countries [8,10,14,15]. Table 4 shows the difference for HCV prevalence among DC in Northwestern European countries (UK, Germany) Southwestern European countries (Italy, Spain) and different Eastern European countries $[8-11,14,16]$. 
In the majority of the Eastern countries, the prevalence is over $40 \%$, with more than $70 \%$ in Romania and Moldavia. Unlike HBV the HCV prevalence in the general population of Eastern countries is in some cases lower than in Western countries (Table 4) [8, 22-25].

\section{Discussion}

The prevalence of viral hepatitis and other agents among ESRD patients in the current study indicates a very high level of endemicity. Twenty-one per cent of patients were found to be $\mathrm{HBsAg}$ carriers and more than $78 \%$ had been exposed to the virus (anti-HBc positive), with a sex- and age-adjusted six-fold risk when compared to non-haemodialysis patients. In analysing the data in the literature, it was found that approximately $20 \%$ of dialysis patients are chronic carriers of HBV in Eastern Europe, compared to approximately $4 \%$ in Western countries. On the other hand, the general population carriage is at least three times higher than in Western Europe (Table 3) [17-20].

Kosovo is a country with a low prevalence of HCV infection $[12,21]$. This was reflected in the group of non-hemodialysis patients, where the prevalence of HCV was as low as $1 \%$. Nevertheless, the prevalence of HCV in dialysed patients was strikingly high (86\%). It was not possible to calculate the OR with the observed numbers. However, the great difference should suggest that, even taking into account potential differences between the two groups compared in this study, hemodialysis should be considered a strong risk factor for HCV infection, in line with the results of other studies carried out in Eastern European countries [8-10,15]. The HCV prevalence in DC in Western versus Eastern countries differs: from around $2 \%$ in Germany and the United Kingdom (UK) to $20 \%$ in Spain and Italy and up to $50-70 \%$ in Eastern European countries $[8,15]$. In the Dialysis Outcomes and Practice Patterns Study (DOPPS), the mean prevalence of HCV infection in five Western European countries (France, Germany, Italy, Spain and the UK), Japan and the United States (US) was 13\% [16].

In Europe, the overall prevalence of HBV and HCV in ESRD patients has been decreasing over the years as a result of HBV vaccination, routine screening of blood products, and the use of recombinant human erythropoietin $[6,11,16]$. Guidelines for universal precautions - 'Recommendations for preventing transmission of infections among chronic hemodialysis patients' - had been initially recommended by the US Centers for Disease Control and Prevention (US, CDC) in 1985 and successively updated [26]. In Kosovo, erythropoietin started to be used in 2004 but with marked differences between centres. The percentage of haemodialysis patients receiving erythropoietin in Kosovo is, to date, less than $50 \%$. The situation appears to be improving slightly, but precise figures are not available. Screening of blood-donors for blood-borne viruses has only been implemented regularly since 2001. No immunisation policy for hepatitis vaccination existed in general in Kosovo before the war. In Kosovo there is the policy for HBV vaccination of haemodialysis patients and medical staff. The lack of available vaccines hampers its implementation; for example, in 2005 the percentage of vaccinated individuals among the 253 health care workers of the Peja hospital was 16.6\% [12]. An important measure for the control of hepatitis infection is the segregation of positive patients and their haemodialysis equipment [27]. Until recently, the lack of resources prevented this practice in Kosovo.

In our study the syphilis prevalence (anti-Treponema pallidum IgG) among dialysed patients was $3 \%$, much higher than the
$0.2 \%$ of non-dialysed subjects. There is little data on syphilis seroprevalence in DC patients. Sexual contact is the primary mode of transmission of syphilis, but blood transfusion, blood contact and accidental inoculations are other modes of infection that place ESRD patients at risk. A report from Taiwan showed a prevalence of syphilis among dialysed patients of 5.6\% [28]. In a more recent study, the syphilis seroprevalence in 167 ESRD patients was $6.7 \%$, more than two times higher than the overall prevalence reported in the general population [29].

HHV-8 is a gamma-herpes virus, closely related to the EpsteinBarr virus. We do not have data to compare our study population with the Kosovar general population. Nevertheless, in nearby Albania, $\mathrm{HHV}-8$ seroprevalence in the general population is reported to be $20 \%$ [30]. Transmission of HHV-8 infection through blood, although suggested, is controversial. A case-control study performed in 97 dialysed patients from Northern Italy found a prevalence of $9.2 \%$ (in this geographic area the prevalence of HHV-8 in blood donors was $12.7 \%$ ) [31]. In Greece, HHV-8 prevalence in 485 dialysed patients was $7.2 \%$ [32]. In Southern Italy, the seroprevalence of HHV-8 among ESRD patients was 27\% (comparable to $25 \%$ as observed in the general population) [33].

In Kosovo, the prevalence of infection from viral hepatitis, HHV-8, HSV-2 and Treponema pallidum among ESRD patients is high, indicating major ongoing nosocomial transmission. Even though this may be a consequence of limited resources available, targeted recommendations could be implemented to improve the current situation:

- rigorous attention should be paid to infection control procedures such as changing gloves between patients and the decontamination of equipment and surfaces after each patient treatment episode;

- all single-use injectable medications and solutions should used on a single patient, and all parenteral medications should be prepared in a clean area separate from potentially contaminated items and surfaces;

- hepatitis B vaccination should be given to all patients and staff [34];

- HBsAg and HCV positive patients and their dialysis equipment should be segregated;

- periodic diagnostic testing of patients and healthcare workers needs to be carried out;

- dialysis providers should be aware of their responsibility to report clusters of infections to the local health authorities, as the failure to report illness clusters can result in delays in the recognition of disease outbreaks; and

- training for health care workers should be implemented periodically.

Our study has several limitations that have to be emphasised. As the data were restricted to one DC, the results presented here cannot be considered indicative for Kosovo as a whole and figures on serological status of the health personnel are not available. Furthermore data on the incidence of infectious diseases after the regular screening of blood transfusion for blood-borne viruses were implemented (2001) are not available; and information on possible risk factors is also missing. In Kosovo further studies on the prevalence and incidence of blood borne viruses among ESRD patients are needed, involving more than one DC, and exploring possible risk factors in these patients and settings. 


\section{References}

1. Bilefsky D. Kosovo declares its independence from Serbia. The New York Times. 2008 Feb 18. . Available from: http://www.nytimes.com/2008/02/18/world/ europe/18kosovo.html

2. World Bank. Kosovo Poverty Assessment. Volume II: Estimating trends from non-comparable data. October 2007. Available from: http://siteresources. worldbank.org/INTKOSOVO/Country\%2OHome/21541688/KosovoPAvol2.pdf

3. Health Statistics 2007. Kosovo Government, Ministry of Public Administration. Statistical Office of Kosovo. Pristine 2008.

4. Rutkowski B. Changing pattern of end-stage renal disease in central and eastern Europe. Nephrol Dial Transplant. 2000;15(2):156-160.

5. Wong PN, Fung TT, Mak SK, Lo KY, Tong GM, Wong Y, et al. Hepatitis B virus infection in dialysis patients J Gastroenterol Hepat. 2005;20(11):1641-51.

6. Sulowicz W, Radziszewski A, Chowaniec E. Hepatitis C virus infection in dialysis patients. Hemodialysis Internat. 2007;11(3):286-95.

7. Fabrizi F, Poordad FF, Martin P. Hepatitis C infection and the patient with endstage renal disease. Hepatology. 2002;36(1):3-10.

8. Covic A, Iancu L, Apetrei C, Scripcaru D, Volovat C, Mititiuc I, et al. Hepatitis virus infection in haemodialysis patients from Moldavia. Nephrol Dial Transplant. 1999;14(1):40-5.

9. Atanasova M, Kardjeva V, Kicheva M, Draganov M, Stoyanov T, Kostadinova T, et al. Hepatitis $C$ virus infection in patients from the haemodialysis clinic of a medical university, Plovdiv, Bulgaria. 18th European Congress of Clinical Microbiology and Infectious Diseases (ESCMID). Barcelona, Spain, 19-22 April 2008. Abstract n. R2480. Available from: http://www.blackwellpublishing.com/ eccmid18/PDFs/Abstracts_accepted_for_publication_only.pdf

10. Djukanović L, Radović M, Baković J, Budosan I, Bukvić D, Cveticanin A, et al. Epidemiology of end-stage renal disease and current status of hemodialysis in Yugoslavia. Int J Artif Organs. 2002;25(9):852-9.

11. Jadoul M, Poignet JL, Geddes C, Locatelli F, Medin C, Krajewska M, et al. HCV Collaborative Group. The changing epidemiology of hepatitis C virus (HCV) infection in haemodialysis: European multicentre study. Nephrol Dial Transplant. 2004;19(4):904-9.

12. Quaglio GL, Ramadani N, Pattaro C, Cami A, Dentico P, Volpe A, et al. Prevalence and risk factors for viral hepatitis in the Kosovarian population: implications for health policy. J Med Virol. 2008;80(5):833-40.

13. R Development Core Team. 2008. R: A Language and Environment for Statistical Computing. Vienna, Austria: R Foundation for Statistical Computing.Available from: http://www.r-project.org/

14. Burdick RA, Bragg-Gresham JL, Woods JD, Hedderwick SA, Kurokawa K, Combe C, et al. Patterns of hepatitis B prevalence and seroconversion in hemodialysis units from three continents: the DOPPS. Kidney Int. 2003;63(6):2222-9.

15. Vladutiu DS, Cosa A, Neamtu A, State D, Braila M, Gherman M, et al. Infections with hepatitis $B$ and $C$ viruses in patients on maintenance dialysis in Romania and in former communist countries: yellow spots on a blank map? J Viral Hepat. 2000;7(4):313-9.

16. Fissell RB, Bragg-Gresham JI, Woods JD, Jadoul M, Brenda Gillespie B, Hedderwick SA, et al. Patterns of hepatitis $C$ prevalence and seroconversion in hemodialysis units from three continents: The DOPPS. Kidney International 2004;65(6): 2335-42.

17. Thierfelder W, Hellenbrand W, Meisel H, Schreier E, Dortschy R. Prevalence of markers for hepatitis A, B and C in the German population. Results of the German National Health Interview and Examination Survey 1998. Eur J Epidemiol. 2001;17(5):429-35.

18. Eurohep.net project website. Available from: http://www.eurohep.net/

19. Solà R, Cruz De Castro E, Hombrados M, Planas R, Coll S, Jardí R, et al. [Prevalence of hepatitis $B$ and hepatitis $C$ viruses in different counties of Catalonia, Spain: cross-sectional study]. [Article in Spanish]. Med Clin (Barc). 2002;119(3):90-5.

20. Emiroglu N. Immunization Programme and Prevention/control of HepB European Region of WHO. EUROHEP.NET meeting, April 21, 2005. Powerpoint presentation. Available from: http://www.eurohep.net/files/presentations/ MALS61Emiroglu.pdf.

21. Chironna M, Germinario C, Lopalco PL, Carrozzini F, Quarto M. Prevalence of hepatitis virus infections in Kosovar refugees. Int J Infect Dis. 2001;5(4):20913.

22. Müller Z, Deák J, Horányi M, Szekeres E, Nagy I, Ozsvár Z, et al. The detection of hepatitis C virus in South Hungary. J Clin Virology. 2001;20(1-2):81-3.

23. Esteban JI, Sauleda S, Quer J. The changing epidemiology of hepatitis $C$ virus infection in Europe. J Hepatol. 2008;48(1):148-62.

24. Bird SM, Goldberg DJ, Hutchinson SJ. Projecting severe sequelae of injectionrelated hepatitis $C$ virus epidemic in the UK. Part 2: Preliminary UK estimates of prevalent injection related hepatitis $C$ carriers, and derivation of progression rates to liver cirrhosis by gender and age at hepatitis $C$ virus infection. J Epidemiol Biostat. 2001;6(3):267-77.
25. Dominguez A, Bruguera M, Vidal J, Plans P, Salleras L. Community-based seroepidemiological survey of HCV infection in Catalonia, Spain. J Med Virol. 2001;65(4):688-93.

26. Centers for Disease Control and Prevention: Recommendations for preventing transmission of infections among chronic hemodialysis patients. MMWR Morb Mortal Wkly Rep. 2001;50(RR5);1-43.

27. Tang S, Lai KN. Chronic viral hepatitis in hemodialysis patients. Hemodial Int. 2005;9(2):169-79.

28. Lee CT, Lam KK, Liao SC, Chen JB, Hsu KT. The significance of syphilis serology tests on long-term hemodialysis patients. Changgeng Yi Xue Za Zhi. 1998;21(4):447-52.

29. Saxena AK, Panhotra BR, Naguib M, Uzzaman W, Al MK. Nosocomial transmission of syphilis during haemodialysis in a developing country. Scandinavian J Inf Dis. 2002;34(2):88-92.

30. Schinaia N, Kodra Y, Sarmati L, Andreoni M, Bino S, Qyra S, et al. Prevalence of HHV-8 infection in Albanian adults and association with HBV and HCV. Eur J Epidemiol. 2004;19(5):467-9.

31. Luppi M, Vandelli L, Whitby D. Human herpesvirus-8 infection in haemodialysis patients from northern Italy. Kidney Int. 1999;55(1):340.

32. Zavitsanou A, Sypsa V, Petrodaskalaki M, Psichogiou M, Katsoulidou A, Boletis $\mathrm{J}$, et al. Human herpesvirus 8 infection in hemodialysis patients. Am J Kidney Dis. 2006;47(1):167-70.

33. Di Stefano M, Fiore JR, Pepe V, Cantatore S, Ingrassia F, Stallone G, et al. A search for antibodies to HHV- 8 in hemodialysis patients from South-Eastern Italy argues against HHV-8 spread in hemodialysis units. J Clin Virol. 2006;37(1):75-6.

34. Kane M. Global programme for control of hepatitis B infection. Vaccine. 1995;13 Suppl 1:S47-9. 